\title{
Technique
}

\section{Alternative Approach To Needle Placement In Spinal Cord Stimulator Trial/Implantation}

\author{
Jie Zhu, MD¹, Frank Falco, MD ${ }^{1,2}$ C. Obi Onyewu, MD¹, Youssef Josephson, DO², \\ Renato Vesga, MD1, and Rajesh Jari, $\mathrm{MD}^{2}$
}

From: ${ }^{1}$ Mid Atlantic Spine \& Pain Physicians, Newark, NJ; and ${ }^{2}$ Temple University Hospital, Philadelphia, PA.

Dr. Zhu, Dr. Onyewu, and Dr. Vesga are Attending Physicians, Mid Atlantic Spine \& Pain Physicians, Newark, DE and Elkton, MD; Faculty, Pain Medicine Fellowship Program, Temple University Hospital, Philadelphia, PA; Adjunct Assistant Professors, Temple University Medical School, Philadelphia, PA. Dr. Falco is Medical Director, Mid Atlantic Spine \& Pain Physicians, Newark, DE and Elkton, MD; Director, Pain Medicine Fellowship Program, Temple University Hospital, Philadelphia, PA; Adjunct Associate Professor, Temple University Medical School, Philadelphia, PA.

Dr. Josephson and Dr. Jari are Fellows,

Pain Medicine Fellowship Program, Temple University Hospital, Philadelphia,

PA.

Address correspondence: Jie Zhu, MD 139 E. Chestnut Hill Rd. Newark, DE 19713 Email: zzzzjim@gmail.com

Disclaimer: This study did not receive any funding and is HIPAA compliant. Conflict of interest: None.

Manuscript received: $08 / 17 / 2010$ Revised manuscript received: 10/30/2010 Accepted for publication: $12 / 17 / 2010$

Free full manuscript: www.painphysicianjournal.com
Neuromodulation with spinal cord stimulation is a proven, cost effective treatment for the management of chronic radicular low back pain from failed low back surgery syndrome and other neuropathic pain conditions. The traditionally instructed method for percutaneous spinal cord stimulator lead placement promotes the use of a "loss of resistance" technique under anteroposterior fluoroscopic guidance to assure midline lead placement and proper entry into the epidural space. Loss of resistance is a reliable method to locate the epidural space in most clinical situations. However, in certain circumstances such as a congenital underdeveloped ligamentum flavum or defects of the ligamentum flavum, sometimes occurring after lumbar spine surgery, it might become difficult to use a loss of resistance technique to locate the epidural space. In this case, the level of resistance might not be clear. Further, a false loss of resistance might occur between changes in fascial planes that might lead to the uncertainty of needle depth. This paper introduces an alternative method for needle placement for spinal cord stimulator (SCS) trials and implantation without using the traditional loss of resistance technique. The technique allows for precise visual monitoring of the Tuohy needle tip under fluoroscopy to gauge needle depth as it enters into the tissue and the epidural space based on anatomic structural landmarks. This method allows for multiple lead placement or single lead insertion multiple times in the same interlaminar space. This is an alternative approach to the loss of resistance technique based on the fluoroscopic landmarks. Theoretically, this should be a safer approach for accessing the epidural space; however, further studies are needed to evaluate its safety.

Key words: spinal cord stimulator, loss of resistance, epidural access, lumbar radicular symptoms of lower limbs, neuromodulation, posterior column stimulator

Pain Physician 2011; 14:45-53

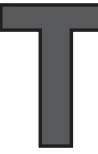
he goal of this article is to describe the relevant anatomy and method for precise needle placement under the lateral view of fluoroscopy for the placement of percutaneous spinal cord stimulation (SCS) leads (Fig. 1). The discussion of risks, potential complications, and benefits from this approach are beyond the scope of this article. Further studies are needed to evaluate the safety of this approach. Readers should carefully evaluate this approach with their medical knowledge and 


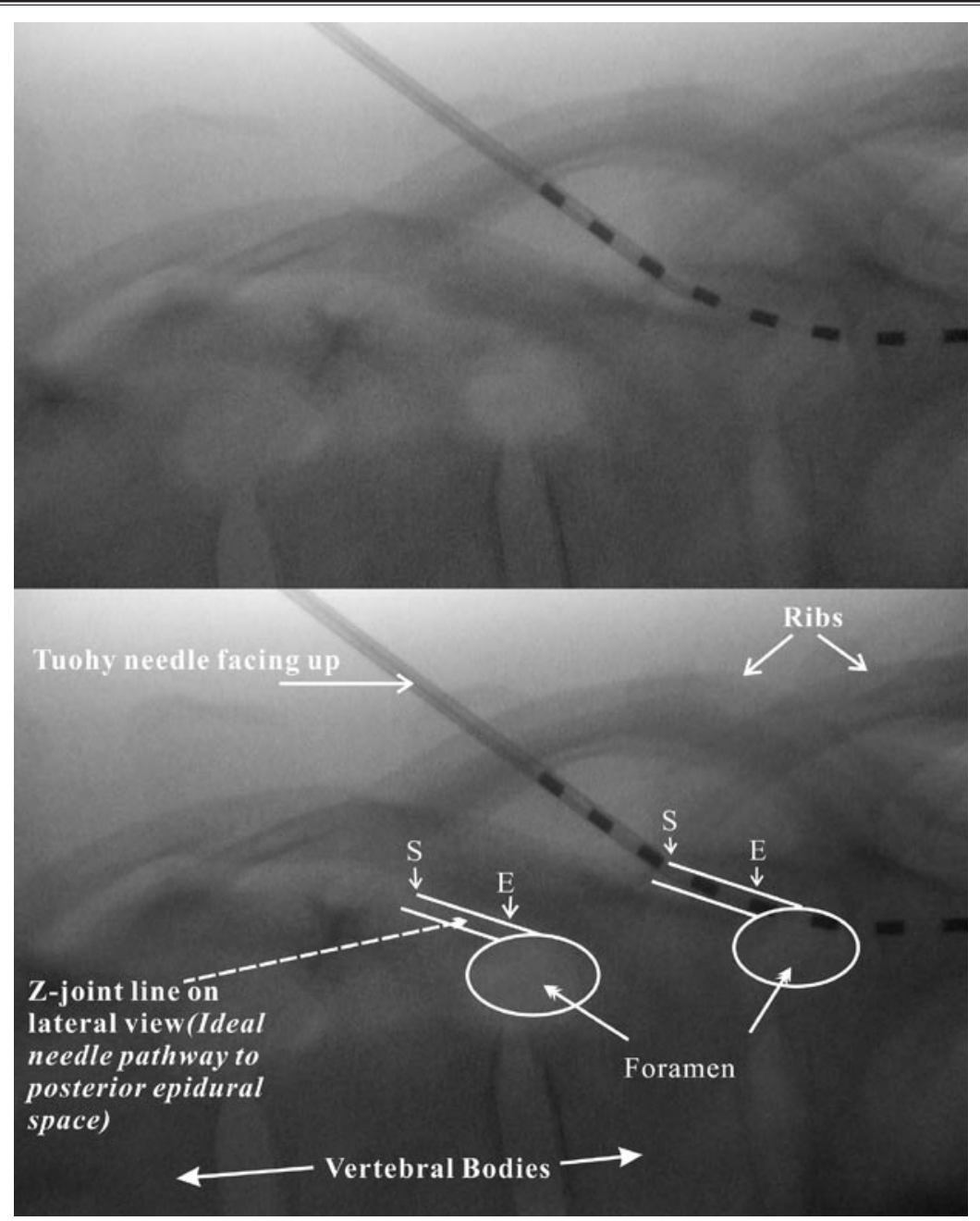

Fig. 1. The lateral view of the spine. S. The starting point to attempt to insert the SCS lead to epidural space at the base of superior articulating process of the target Z-joint. E point. The tip of the superior articulating process of the target Z-joint. It is high risk for penetration of the dural sac if the needle tip is close to or beyond this point. E means the end point to advance the needle.

experiences to understand the risks, benefits, and potential complications that might be encountered in this approach before using it in their clinical work.

Neuromodulation with spinal cord stimulation is a proven cost-effective treatment for the management of common conditions such as chronic radicular leg pain from failed back surgery syndrome, complex regional pain syndrome, or other painful neuropathic pain syndromes $(1,2)$. The traditionally instructed method for percutaneous spinal cord stimulator lead placement promotes the use of a "loss of resistance" (LOR) technique under anteroposterior (AP) fluoroscopic guidance to assure midline lead placement and proper entry into the epidural space. The LOR technique has been used since the early twentieth century and is the most common method for entering the epidural space. However, the LOR technique was developed at a time when fluoroscopy was either not yet widely available or circumstances would not allowed for C-arm fluoroscopy use, e.g., pregnancy. This technique relies on the denseness of the ligamentum flavum and the sudden absence of resistance experienced during ballottement of a syringe filled with saline (with or without an air bubble) or air once through the ligament $(3,4)$. Occasionally it is difficult to use LOR with certain clinical circumstances such as obesity, patients with an abnormal interlaminar 


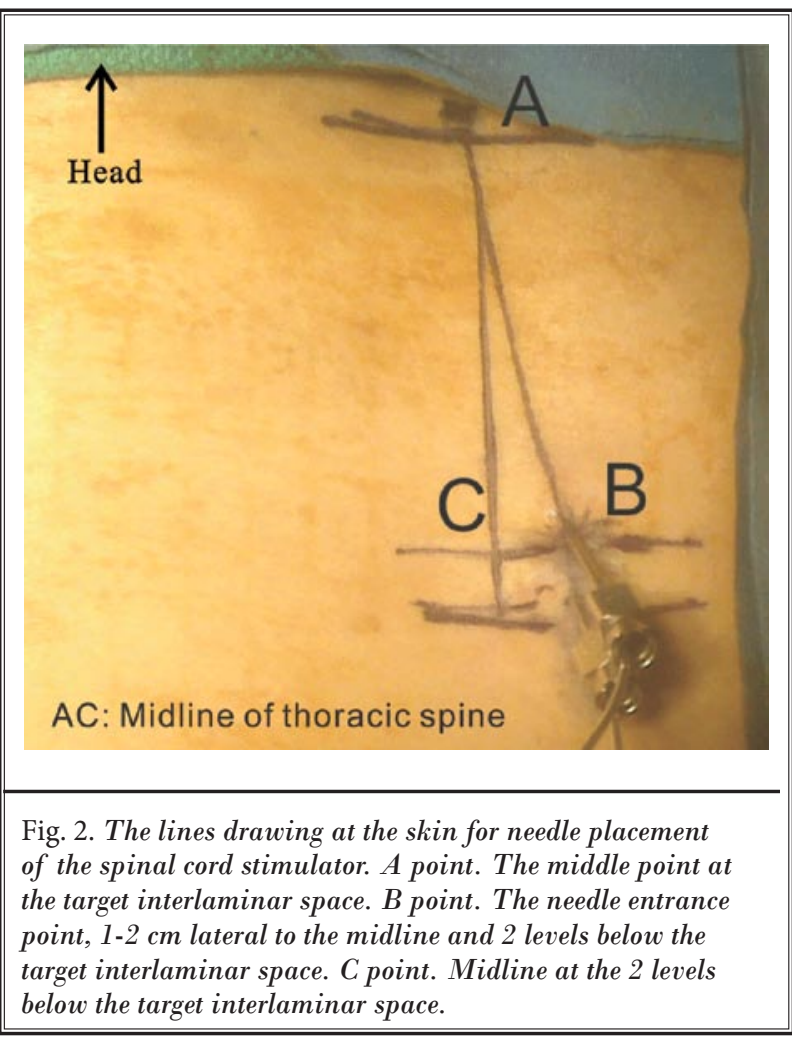

opening at the anteroposterior fluoroscopic views, or patients with changes to the integrity of the ligamentum flavum as might occur with previous spinal surgery. Further, a false loss of resistance might occur between changes in fascial planes that might lead to uncertainty of needle depth (5). In this technique paper, we present an alternative approach for percutaneous lead placement mainly utilizing a lateral view of fluoroscopy to precisely monitor the Tuohy needle tip as it enters the epidural space without using loss of resistance. One potential advantage of this approach is that one can visualize the needle tip and is able to gauge its depth in real time while entering the epidural space. A second potential advantage of this technique is the ability to use the same target interlaminar space repeatedly for subsequent lead placement or for lead reinsertion since this method does not rely on an intact ligamentum flavum for epidural placement.

\section{Method}

\section{Step 1}

The patient is first positioned on the table in the prone position. The field is then prepped and draped. The target interlaminar space is visualized under AP flu-

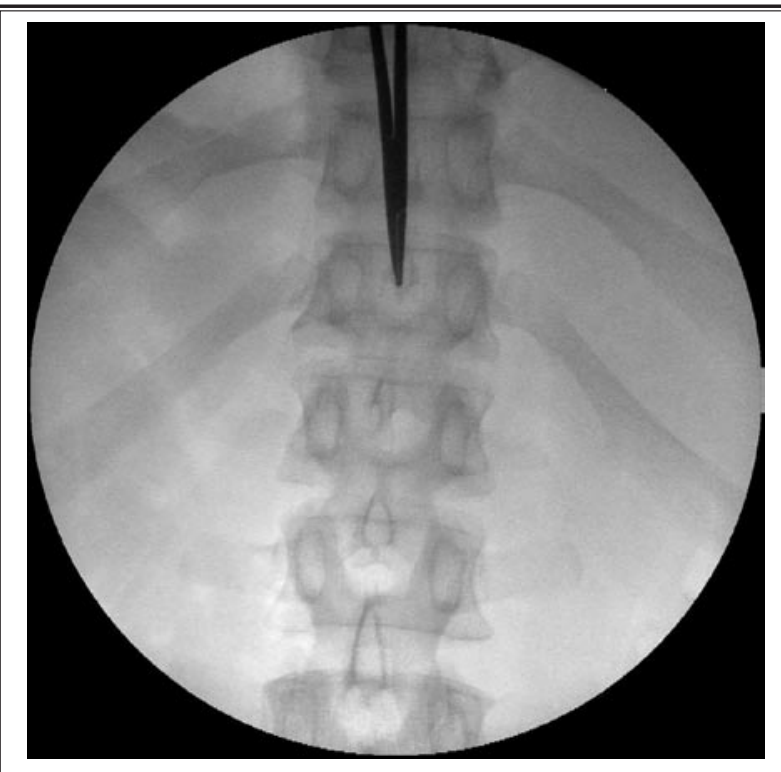

Fig. 3. A point on the skin is the corresponding point to the tip of the spinous process above the target interlaminar space on the AP view of fluoroscopy.

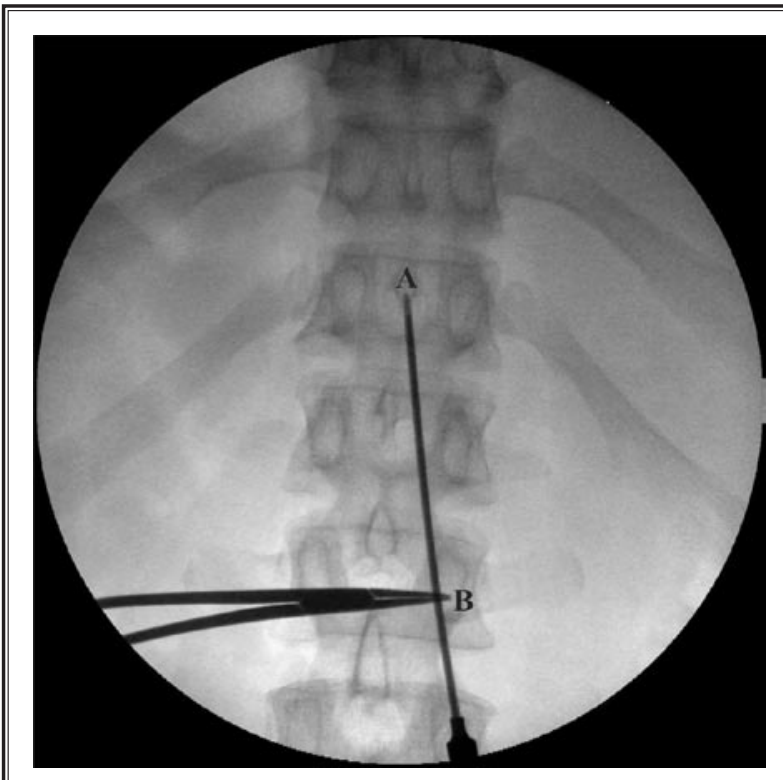

Fig. 4. The trajectory line on the skin. The corresponding line to the Tuohy needle under the AP view of fluoroscopy. $B$ point. The skin entry point of the needle on the AP view of fluoroscopy.

oroscopic guidance, most commonly the T12- L1 interlaminar space. The target point, which is slightly caudal to the T12 spinous process (Figs. 2 and 4, A point) 
of the interlaminar space, is marked on the skin using a sterile skin marker. The Tuohy needle entry point on the skin (Fig. 2, B point; Fig. 4, B point) is marked on the skin at 2 full pedicle lengths below the desired target level and approximately $1-2 \mathrm{~cm}$ off of midline. It must not be shorter than $3 / 4$ length of the needle from the target epidural entry point (Fig. 2 and 4, A point.) The line between the 2 points (Figs. 2 and 4, $A B$ line) is then connected using the skin marker. We will title this line as the "trajectory line" and it will serve as the skin guide for proper alignment while advancing the needle cephalad (in an AP view). Midline (Fig. 2, AC) is further drawn as a reference. The angle BAC (Fig. 2) should be approximately 15-20 degrees.

\section{Step 2}

The skin is anesthetized. Next, a modified Tuohy needle from the SCS kit is inserted with the bevel facing up. The needle angle to the skin should be less than 20-30 degrees in the AP direction. The needle is advanced following the trajectory line (Figs. 2 and 4) under the AP fluoroscopic guidance until the needle has reached the point caudal to the target interlaminar opening (Fig. 5). The fluoroscope is then rotated to a true lateral view, which is obtained when the bilateral ribs line up so that only one rib shadow is viewed for the corresponding bilateral ribs (Fig. 6). The Carm might require tilting and obliquing in a horizontal plane to align the ribs to a single shadow. The zygapophyseal joint (Z-joint) should be identified in full view along with the vertebral foramen and vertebral bodies with associated disc space. The tip of the needle should be superior and caudal to the base of the target Z-joint line in the lateral direction at this time.

\section{Step 3}

The needle is then advanced with the bevel of the needle facing up (Figs. 6 and 7) to the base of the superior articulating process (SAP) of the target Z-joint (Fig. 1, S point and Fig. 7) under the fluoroscopic guidance of the lateral view. An intermittent fluoroscopic view is obtained to ensure that the Tuohy needle is aimed at the midline entrance point in the target interlaminar space along the "trajectory line" in the AP direction. At this point, the stylet is removed and a spinal cord stimulator lead is inserted in a gentle attempt to pass into the epidural space (Fig. 8).

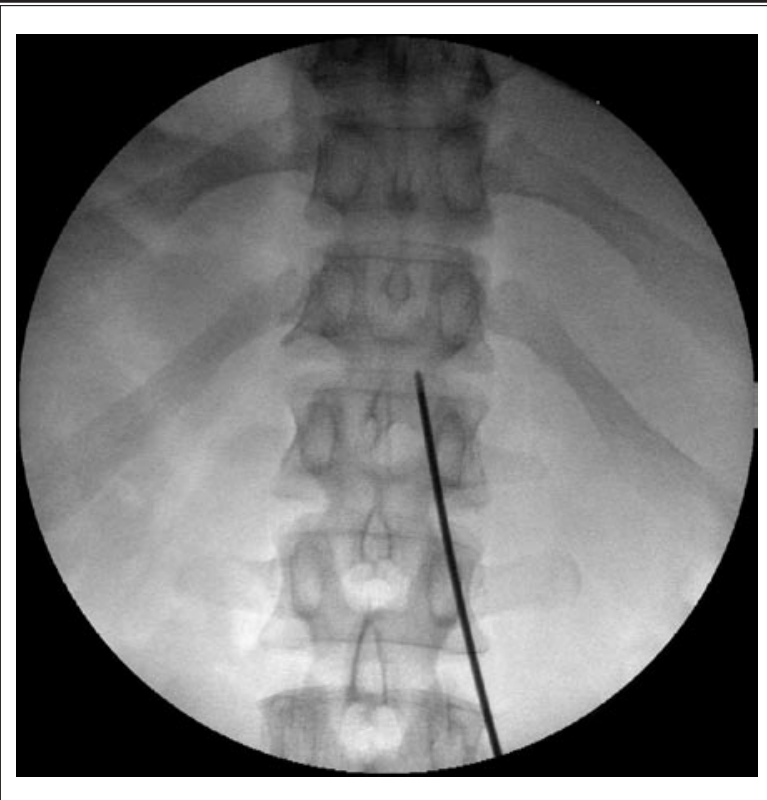

Fig. 5. The Tuohy needle is inserted and advanced following the trajectory line to the level caudal to the target interlaminar space on the AP view before the fluoroscope is rotated to a true lateral view.

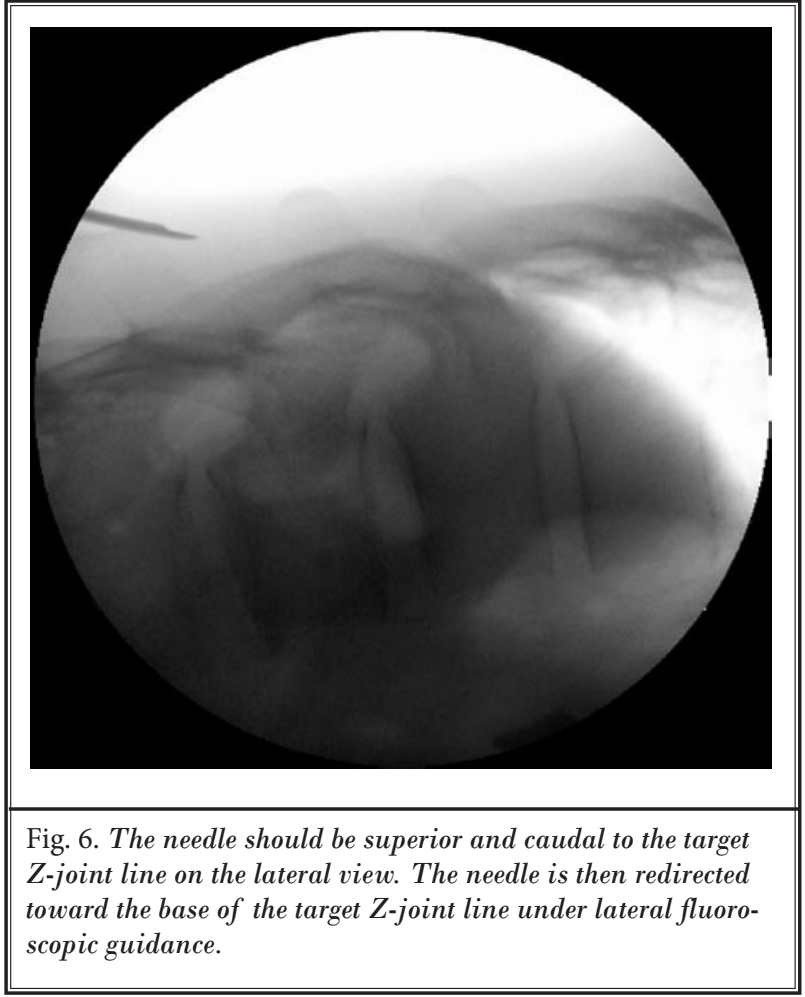

www.painphysicianjournal.com 

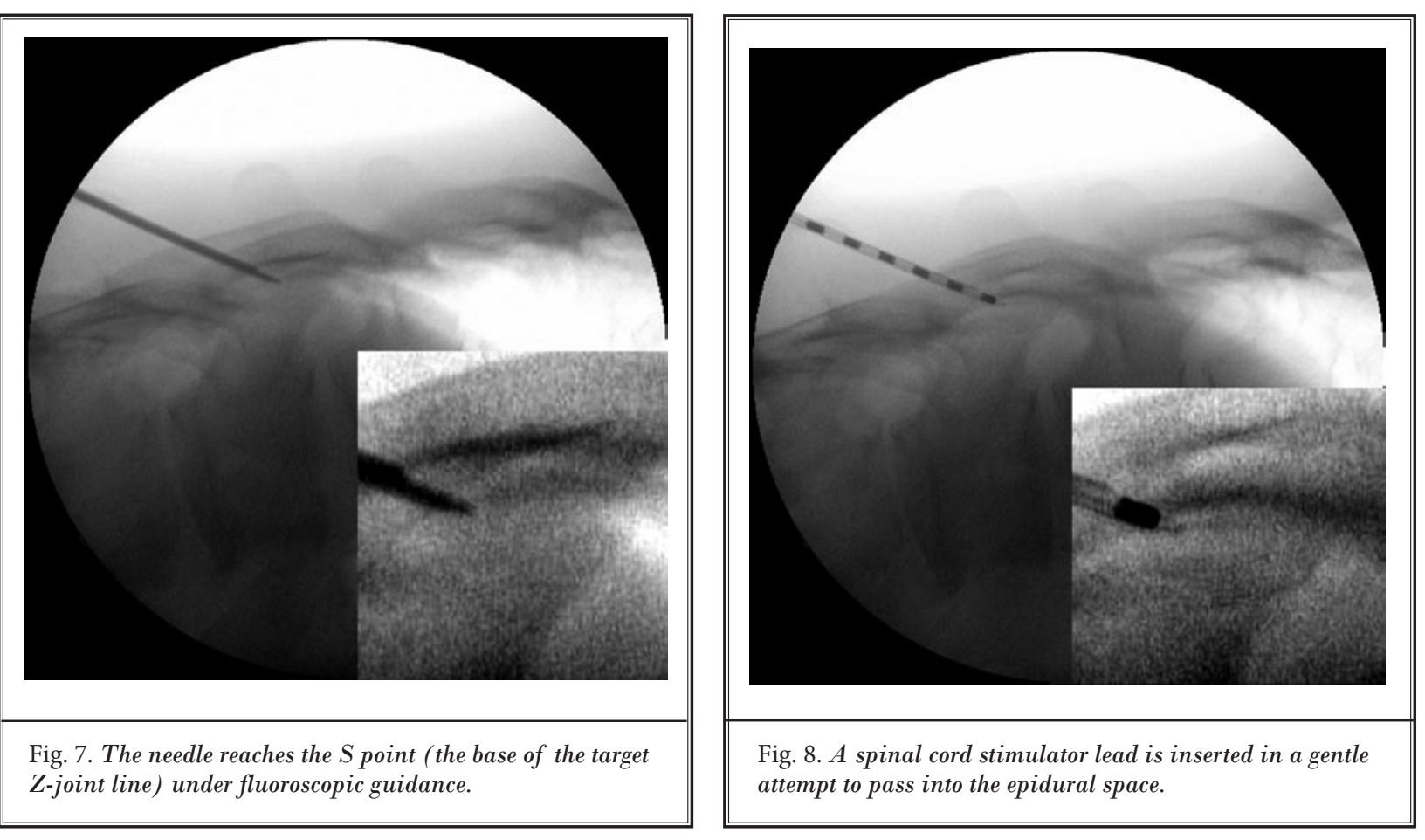

\section{Step 4}

If resistance is felt, the lead is withdrawn to the inside of the Tuohy needle. (Do not force the lead into the tissue or advance the Tuohy needle with the lead in place. Doing so will damage the outer surface of the lead.) The needle is advanced one millimeter at a time along the Z-joint line (Fig. 1, SE) with a lateral fluoroscopic view (Fig. 9). An attempt to advance the lead gently into the epidural space is applied again. The ideal pathway of the Tuohy needle to the posterior epidural space is to follow the Z-joint line from the bottom to the tip under a lateral view of fluoroscopy (Fig. 1).

\section{Step 5}

If resistance is experienced, repeat this step one millimeter at a time (Fig. 10) until the Tuohy needle is advanced into the epidural space (Fig. 11). If the Tuohy needle tip is close to the tip of the superior articulating process of the target Z-joint (Fig. 1, E point) under a lateral view of fluoroscopy, an AP view should be obtained to ensure that the tip of the needle is in the midline of the target interlaminar space. If the needle is found lateral to the midline, it should be withdrawn and repositioned toward the midline. Once the lead is in the epidural space, a series of AP views should be obtained to ensure the lead is positioned at the desired level.

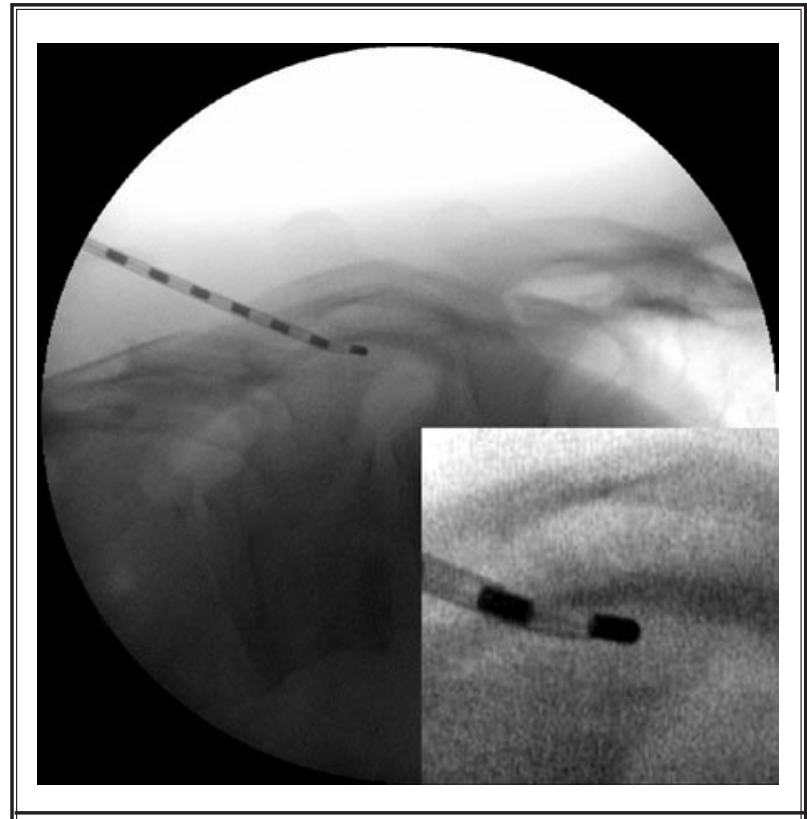

Fig. 9. If resistance is felt, the lead is withdrawn to the inside of the Tuohy needle. The needle is advanced one millimeter at a time along the Z-joint line under lateral fluoroscopic guidance. The lead is advanced in another gentle try to access the epidural space again. 


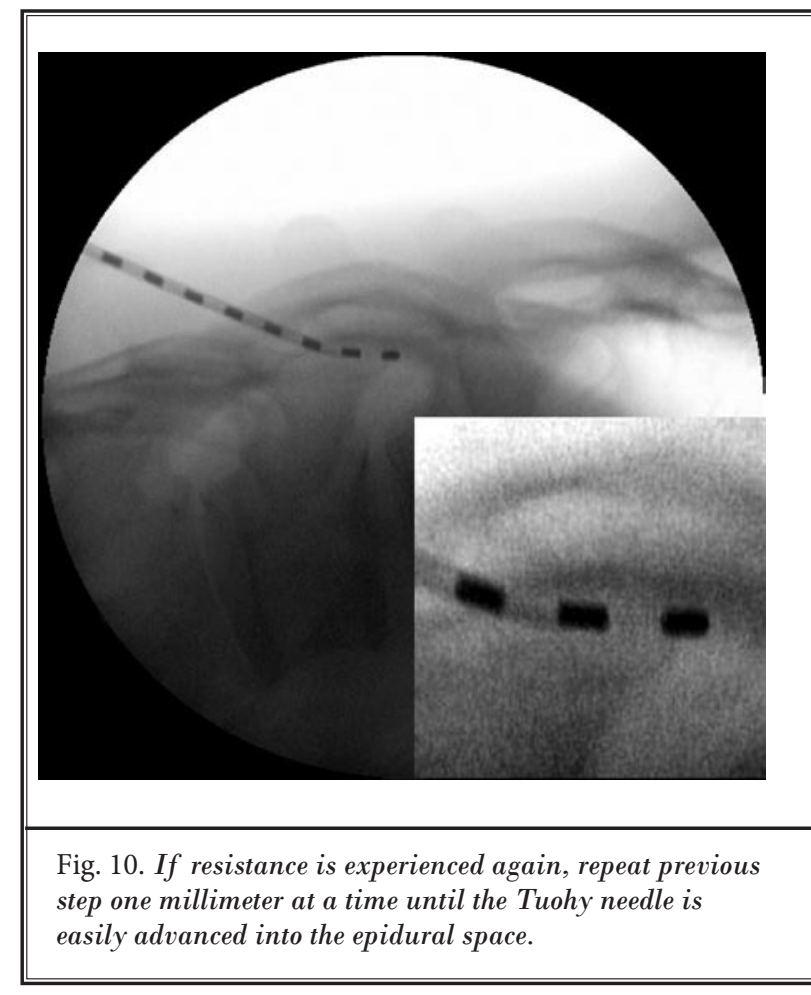

\section{Step 6}

A second lead may be placed in the same interlaminar space on the same side using the first one as guidance for direction (Figs. 12-16). The second Tuohy needle should be inserted below or medial to the first needle. Do not insert the second needle too close to the first one at the skin level. This will ensure that the first needle will not be inadvertently advanced any deeper during manipulation of the second needle. The insertion of the second needle should follow the same technique as the insertion of the first needle.

\section{Key points:}

1) The view of the Z-joint line: The main advantage of this approach is the use of lateral view fluoroscopy to monitor needle depth visually. Occasionally, operators might not see the target Z-joint line at the beginning of the lateral view because the C-arm is not at a right angle to the Z-joint. In this case, the $\mathrm{C}$-arm might be obliqued a little bit to align bilateral ribs together. The $\mathrm{C}$-arm might also need to be tilted slightly to square the endplates of the corresponding vertebral bodies. In the lateral fluoroscopic view, the Z-joint line, or at least the SAP of the target Z-joint, should be easily identified in full view along with the vertebral foramen and vertebral bodies associated with the disc space.
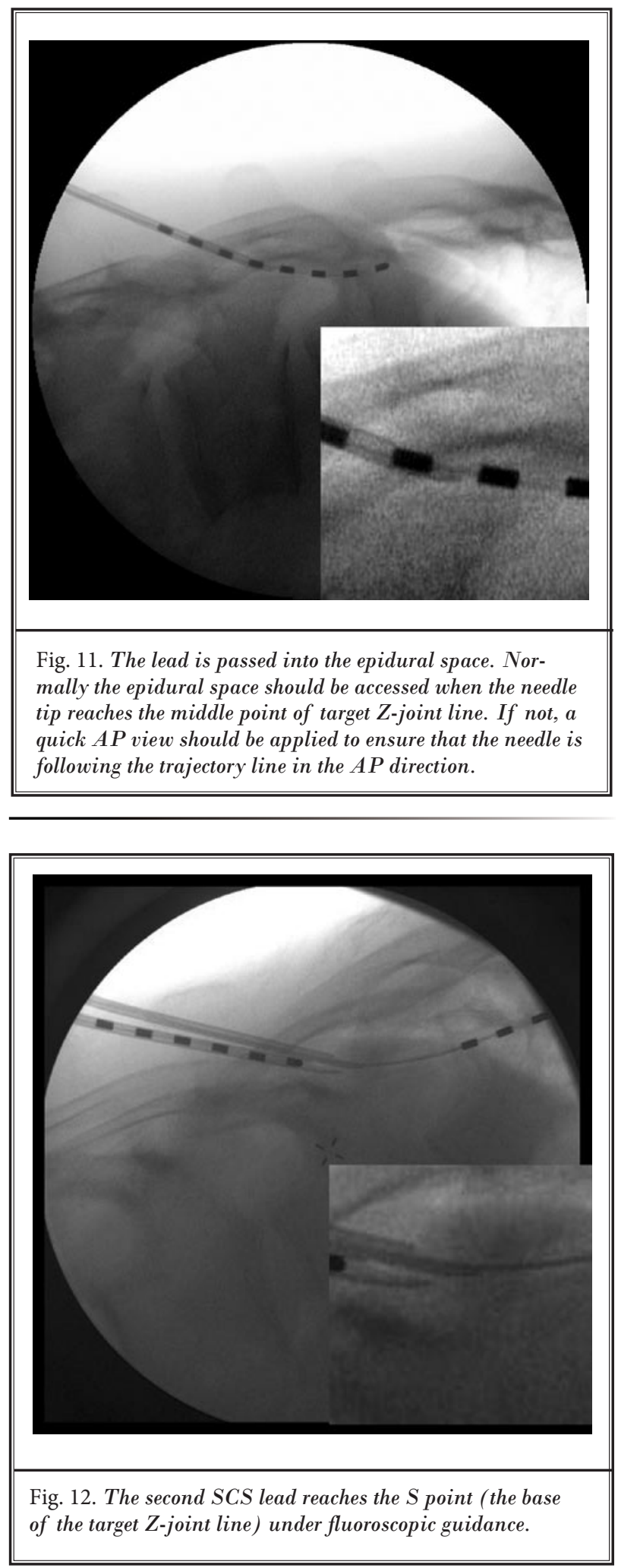

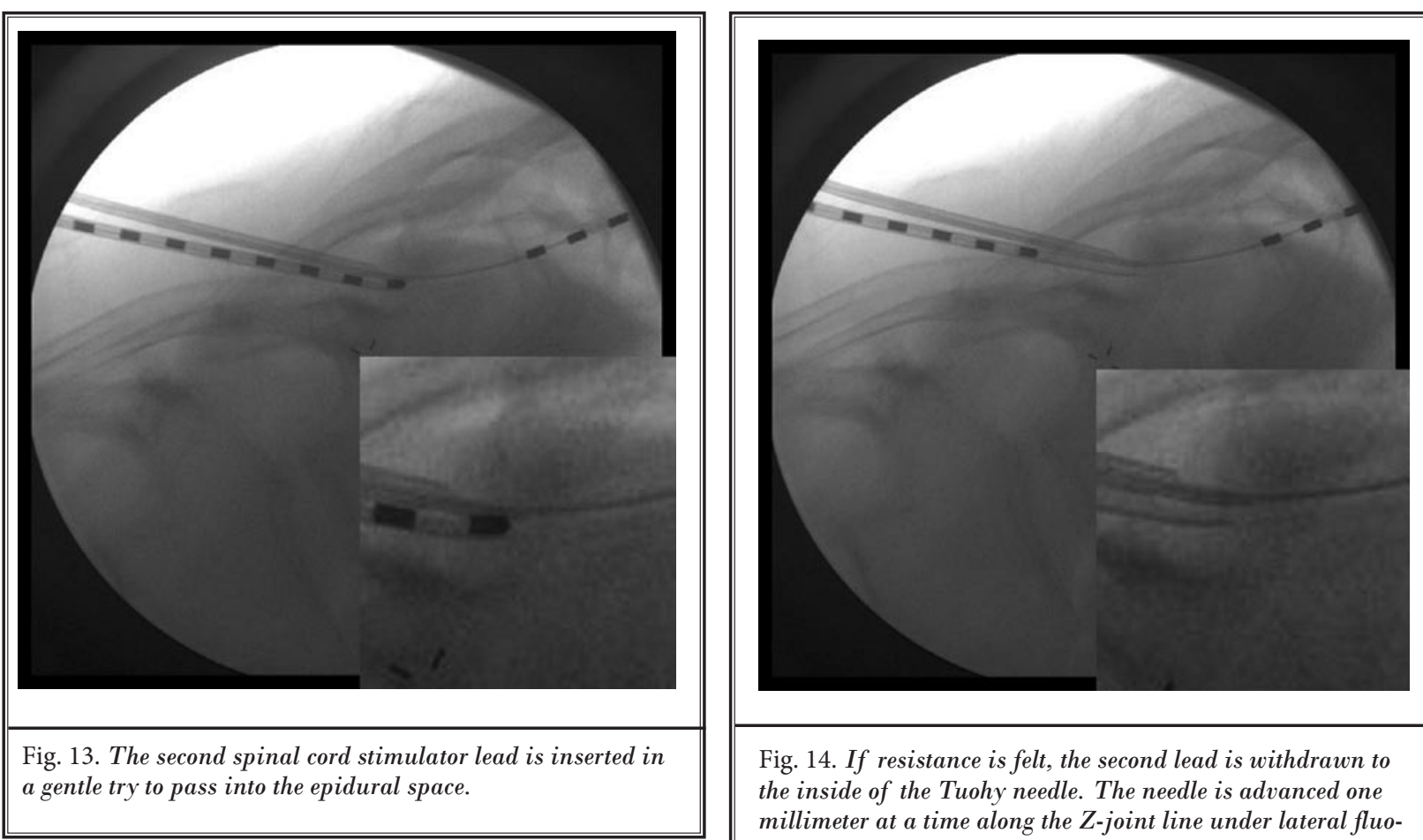

Fig. 14. If resistance is felt, the second lead is withdrawn to the inside of the Tuohy needle. The needle is advanced one millimeter at a time along the Z-joint line under lateral fluoroscopic guidance. The lead is advanced in a gentle attempt to access the epidural space again.

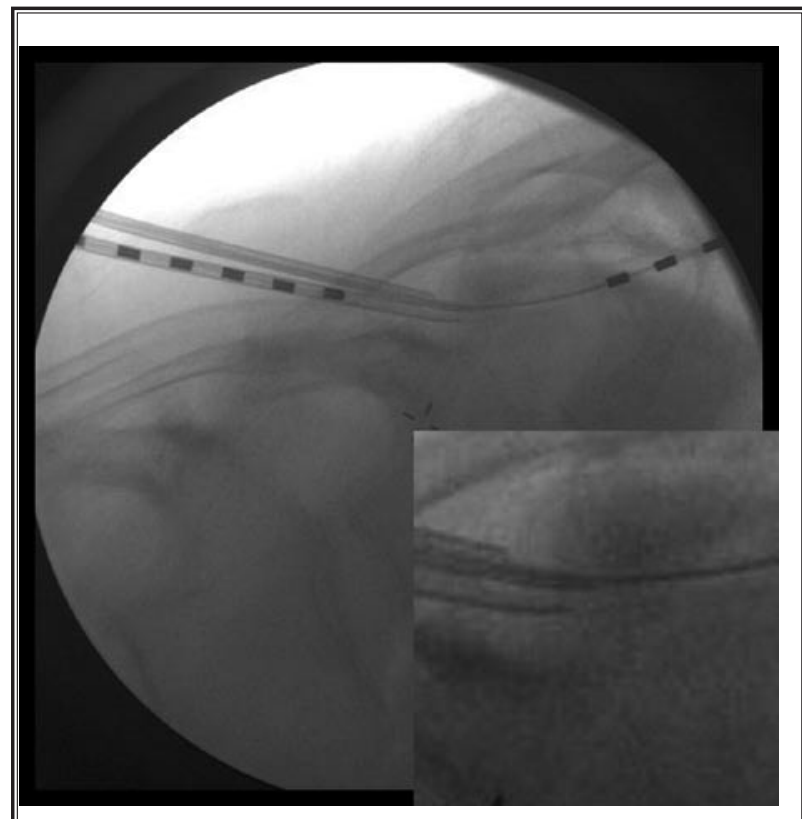

Fig. 15. The second needle is advanced another millimeter to access the posterior epidural space. The tip of the needle is close to the midpoint of the Z-joint line.

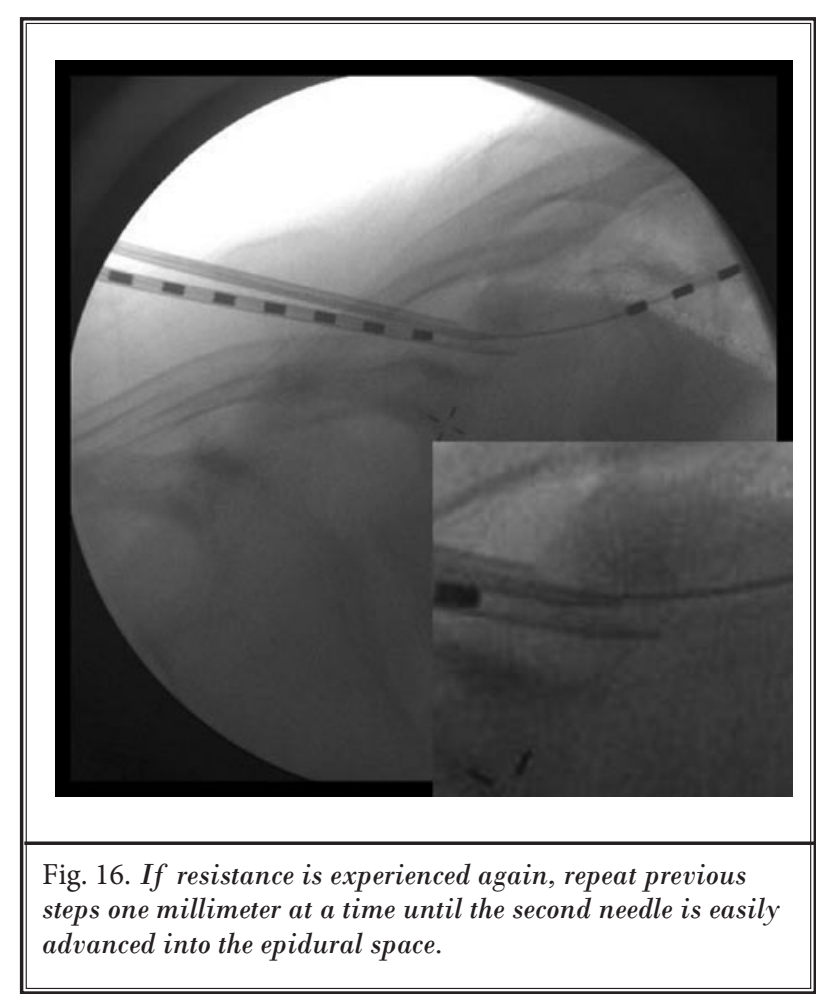


2) Safety area: The position of the Tuohy needle desired for safe entry into the posterior epidural space is between the base of the Z-joint line, or SAP (Fig. $1 \mathrm{~S})$ to the middle of the shadow line of the corresponding Z- joint (Fig. 1 SE) on lateral fluoroscopy. Advancing the needle beyond this point might place the needle tip beyond the epidural space, potentially intrathecally.

3) The re-entry points: Since this approach is based on visual anatomical location and not loss of resistance feel, there is no requirement for an intact ligament to gauge needle depth. When utilizing this approach, a second lead may be placed in the same interlaminar space on the same side. Similarly, if required to reposition the needle, the same space may be entered without a need to change levels.

4. The comparison of the traditional LOR with this approach can be seen in Table 1.

Table 1. Comparison between the Loss of Resistance Approach and the Direct Visualization Approach.

\begin{tabular}{|c|c|c|}
\hline Approach & Loss of Resistance Approach & Direct Visualization Approach \\
\hline Needle insertion & Paramedian approach & $\begin{array}{l}\text { Same paramedian approach with the restricted entry angle ( } 20 \text { - } 30 \text { degrees) and } \\
\text { the skin entry point (Figs. } 2 \text { and } 4, B \text { point) must be } 3 / 4 \text { needle length below the } \\
\text { target interlaminar opening (epidural entry point) at least } 2 \text { full pedicle lengths or } \\
3 / 4 \text { length of the needle below the target epidural entry point }\end{array}$ \\
\hline $\begin{array}{l}\text { Monitoring needle } \\
\text { tip }\end{array}$ & Optional lateral view & $\begin{array}{l}\text { Lateral view with recognized bony landmark (Fig. 1) to visualize the depth of the } \\
\text { needle tip related to the estimated epidural space }\end{array}$ \\
\hline $\begin{array}{l}\text { Locating epidural } \\
\text { space }\end{array}$ & $\begin{array}{l}\text { Using Loss of Resistance approach } \\
\text { without knowing exactly or rela- } \\
\text { tively the needle tip depth inside the } \\
\text { cervical canal }\end{array}$ & $\begin{array}{l}\text { 1. Advance the needle one millimeter at a time after inserting the needle close to } \\
\text { the interlaminar opening (Fig. } 1, S \text { point) and use the SCS lead to try to access the } \\
\text { epidural space gently } \\
\text { 2. Use the lateral view to make sure that the needle is advanced to proper depth }\end{array}$ \\
\hline $\begin{array}{l}\text { Accessing epidural } \\
\text { space }\end{array}$ & $\begin{array}{l}\text { Syringe is removed and an SCS lead } \\
\text { is inserted }\end{array}$ & SCS lead is inserted \\
\hline $\begin{array}{l}\text { Advancing lead inside } \\
\text { of thoracic epidural } \\
\text { space to target level }\end{array}$ & Originally taught approach & Same approach \\
\hline Requirements & Precise manipulation of needle & $\begin{array}{l}\text { 1. Precise manipulation of needle. (Any deviation from trajectory line in AP di- } \\
\text { rection and/or the line from skin entry point to the base of the Z-joint will cause } \\
\text { severe problems when the needle accesses the epidural space) } \\
\text { 2. Thorough knowledge of anatomy of thoracic spine and fluoroscopy }\end{array}$ \\
\hline Common problems & $\begin{array}{l}\text { Many noted problems with this } \\
\text { approach dependant on the user. } \\
\text { (Might be difficult to use Loss of Re- } \\
\text { sistance approach to access epidural } \\
\text { space due to the differences between } \\
\text { patient's body habitus) }\end{array}$ & $\begin{array}{l}\text { 1. The needle is pointing laterally to the target point while being advanced. (The } \\
\text { needle tip will appear lower than usual related with epidural space on the oblique } \\
\text { view of fluoroscopy) } \\
\text { 2. Needle entry point at skin (Figs. } 2 \text { and } 4 \text {, B point) is shorter than } 3 / 4 \text { length of } \\
\text { needle below the target interlaminar opening }\end{array}$ \\
\hline Contraindications & As taught & $\begin{array}{l}\text { 1. Same as paramedian approach } \\
\text { 2. Thoracic spinal stenosis } \\
\text { 3. Do not use it without fully understanding this approach } \\
\text { 4. Lapse of attention might cause serious complications } \\
\text { 5. Switch to Loss of Resistance approach if any difficulty is encountered }\end{array}$ \\
\hline $\begin{array}{l}\text { Risks and potential } \\
\text { complications }\end{array}$ & As taught & $\begin{array}{l}\text { 1. Same as paramedian approach } \\
\text { 2. Paraplegia, death, or other serious consequences could occur from carelessness } \\
\text { or uncertainty with anatomy of thoracic spine or fluoroscopy }\end{array}$ \\
\hline Benefits & As taught & $\begin{array}{l}\text { 1. Same as paramedian approach } \\
\text { 2. The needle may re-enter the epidural space at the same level and same side of } \\
\text { the target interlaminar opening for needle entry point adjustment or subsequent } \\
\text { needle insertion (It does not depend on the integrity of the ligamentum flavum as } \\
\text { the loss of resistance technique does) }\end{array}$ \\
\hline Recommendations & Caution needed & $\begin{array}{l}\text { 1. Thorough anatomic knowledge of thoracic spine, fluoroscopy and caution needed. } \\
\text { 2. Use this approach with Loss of Resistance approach if user has fewer experi- } \\
\text { ences with this approach or is new to thoracic SCS lead insertion. (Do not re- } \\
\text { enter epidural space at the same level and same side of thoracic spine when using } \\
\text { Loss of Resistance only.) }\end{array}$ \\
\hline
\end{tabular}




\section{Discussion}

The LOR technique is a reliable method for localizing the epidural space in most clinical situations. However, in certain circumstances it might be difficult to use an LOR technique to locate the epidural space since the resistance level might be unclear. The false loss of resistance might occur when changes in fascial planes occur that lead to uncertainty of needle depth. This approach allows for precisely monitoring the Tuohy needle depth as it enters into the tissue and the epidural space based on anatomic landmark structures. It also allows for multiple lead placements (Figs. 12-16) or a single lead inserted multiple times in the same interlaminar space on

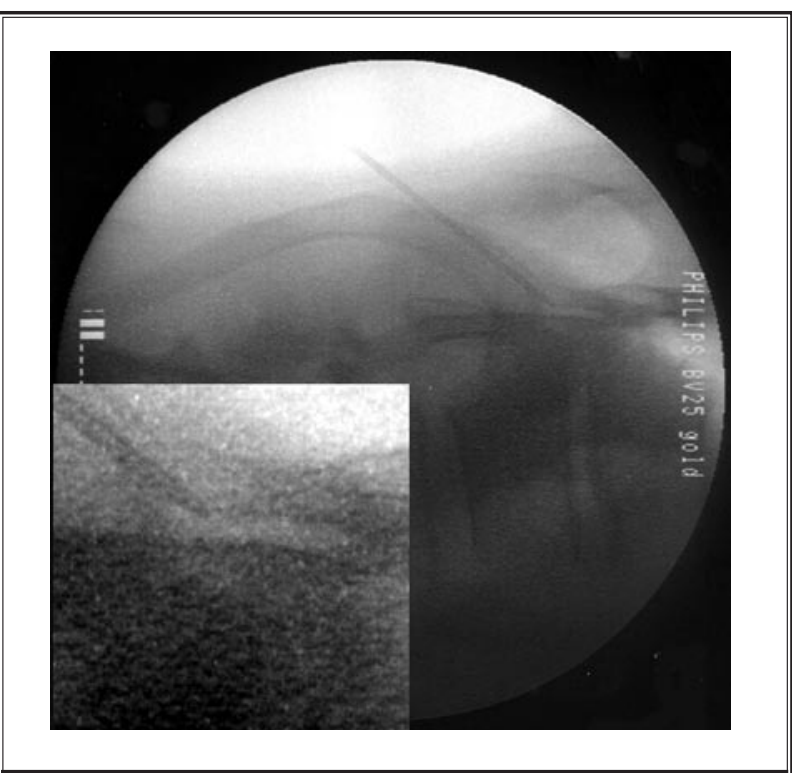

Fig. 17. Thoracic epidural with loss of resistance technique. The Tuohy needle reaches the $S$ point (the base of the target Z-joint line) under fluoroscopic guidance. the same side. It can also be used for thoracic epidural injection with LOR technique under fluoroscopic guidance to monitor the needle tip location (Figs. 17, 18).

\section{Conclusion}

This is an alterative approach to the loss of resistance technique based on fluoroscopic landmarks. The safety and risk assessment of this approach is beyond the scope of this technique report. Theoretically, it should be a safer approach to access the epidural space; however, further studies are needed to evaluate the safety of this method.

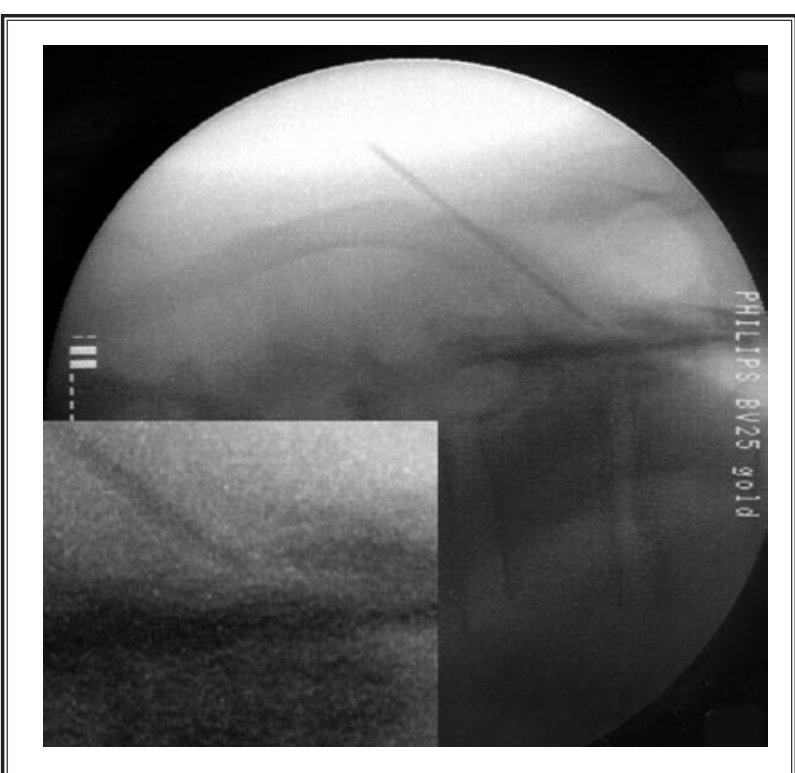

Fig. 18. Thoracic epidural with loss of resistance technique. The posterior thoracic epidural space is highlighted by contrast dye.

\section{References}

1. North RB, Kidd DH, Lee MS, Piantadosi D. Spinal cord stimulation versus reoperation for the failed back surgery syndrome: Initial results. Stereotact Funct Neurosurg 1994; 62:267-272.

2. Kumar K, Taylor RS, Jacques L, Eldabe $\mathrm{S}$, Meglio M, Molet J, Thomson S, O'Callaghan J, Eisenberg E, Milbouw G, Busher E, Fortini G, Richardson J, North RB. Spinal cord stimulation ver- sus conventional medical management for neuropathic pain: A multicentre randomised controlled trial in patients with failed back surgery syndrome. Pain. 2007; 132:179-188.

3. Shenouda PE, Cunningham BJ. Assessing the superiority of saline versus air for use in the epidural loss of resistance technique: A literature review. Reg Anesth Pain Med 2003; 28:48-53.
4. Schier R, Guerra D, Aguilar J, Pratt GF, Hernandez M, Boddu K, Riedel B. Epidural space identification: A meta-analysis of complications after air versus liquid as the medium for loss of resistance. Anesth Analg 2009; 109:20122021.

5. Gupta B, Sharma S, D'souza N, Kaur M. Pseudo loss of resistance in epidural space localization. Saudi J Anaesth 2010; 4:117-118. 
